\title{
Announcement
}

\section{Job Placement for the 21st Century}

\author{
April 2-4, 1997
}

The RRTC on Blindness and Low Vision is sponsoring this national conference which will encompass a wide range of issues concerned with job placement of persons who are blind or visually impaired.

Strategies will be shared for managing the special considerations that may accompany blindness, such as deafness, mental health problems, substance abuse, etc. The Registration Deadline is March 15, 1997.

Location: Tampa Airport Hilton at Metro Center, Tampa, FL, 2225 Lois Avenue. Tel. + 1 (813)877-6688. Free airport transportation.

\section{Agenda highlights.}

- Customer service.

- Providing follow-up service.

- Panel: Case studies of access technology as a placement tool.

- General sessions: Marketing to employers; Preparing consumers; An employer pespective; Doing job placement; Placement beyond 2000.

- Placement of persons who are blind and/or multi-disabled: special considerations.

- Placement of persons who are blind with mental health problems: special considerations.

- Placement of persons who are deaf-blind: special considerations.

- Placement of persons who are blind with substance abuse: special considerations

\section{Featured speakers}

Dr. Karen Wolffe; Mr. Jerry Miller; Dr. Craig Colvin; Dr. Susan Kelley; Mr. Robert Kelly.

For more information, please contact Ms. Tara Lancy at (601) 325-2001. 